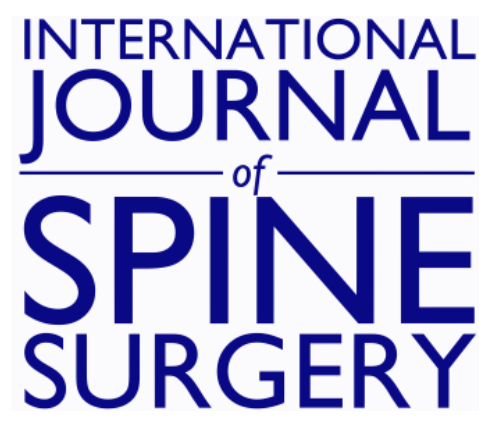

\title{
Efficacy of Anterior Vertebral Body Tethering in Skeletally Mature Children with Adolescent Idiopathic Scoliosis: A Preliminary Report
}

Sajan K. Hegde, Muralidharan Venkatesan, Keyur Kantilal Akbari and Vigneshwara M. Badikillaya

Int J Spine Surg published online 22 September 2021

http://ijssurgery.com/content/early/2021/09/20/8122

This information is current as of April 26, 2023.

Email Alerts Receive free email-alerts when new articles cite this article. Sign up at:

http://ijssurgery.com/alerts

The International Journal of Spine Surgery

2397 Waterbury Circle, Suite 1,

Aurora, IL 60504, Phone: +1-630-375-1432 


\title{
Efficacy of Anterior Vertebral Body Tethering in Skeletally Mature Children with Adolescent Idiopathic Scoliosis: A Preliminary Report
}

\author{
SAJAN K. HEGDE, MS, MURALIDHARAN VENKATESAN, MRCS (ED), MCH, FRCS, KEYUR KANTILAL \\ AKBARI, MS, VIGNESHWARA M. BADIKILLAYA, MS \\ Apollo Hospital, Chennai, India
}

\begin{abstract}
Background: Anterior vertebral body tethering (AVBT) offers a dynamic fusion less correction option for children with adolescent idiopathic scoliosis (AIS). Few existing clinical studies evaluating novel AVBT in skeletally immature children have questioned the midterm efficacy with concerns of overcorrection and curve progression with remaining growth. The current study investigates the effect of this technique in skeletally mature children (Risser $\geq 4$ and Sanders $\geq 7$ ) with AIS with limited remaining growth potential.

Methods: We evaluated skeletally mature children with AIS who underwent the AVBT technique for a single structural major curve between $40^{\circ}$ and $80^{\circ}$ with $\geq 50 \%$ flexibility on dynamic radiographs and a minimum of 1 year of follow-up. Pertinent clinical and radiographic data collected include skeletal maturity, curve type, Cobb angle, sagittal parameters, and a patient-reported outcome measure Scoliosis Research Society-22 (SRS-22) questionnaire.

Results: All 10 children were female with a mean age of $14.9 \pm 2.7$ years at the time of surgery. The mean followup was $24.1 \pm 3.6$ months. The mean Risser and Sanders scores were $4.2 \pm 0.6$ and $7.2 \pm 0.6$, respectively. Three patients had major thoracic curves, and 7 patients had thoracolumbar/lumbar curves. Cranial and caudal instrumented levels were T5 and L4. Mean preoperative Cobb's angle was $52.0^{\circ} \pm 11.6^{\circ}$ and was corrected to $15.9^{\circ} \pm 6.8^{\circ}$ on the first erect postoperative radiograph, with stabilization of corrected curve at the 1-year follow-up (mean Cobb's angle of $15.3^{\circ}$ $\left.\pm 8.7^{\circ}\right)$. Mean preoperative and postoperative SRS-22 scores were $78.0 \pm 3.2$ and $92.5 \pm 3.1$, respectively $(P<.01)$. No complications were noted until the last follow-up.
\end{abstract}

Conclusion: Our preliminary experience with this novel AVBT as an alternative technique to fusion to stabilize progressive idiopathic scoliosis in skeletally mature children is promising.

Level of Evidence: 4.

New Technology

Keywords: nonfusion correction, anterior vertebral body tethering, adolescent idiopathic scoliosis, VBT, fusion less

\section{INTRODUCTION}

Anterior vertebral body tethering (AVBT) is a novel, dynamic nonfusion growth modulation technique developed to treat adolescent idiopathic scoliosis (AIS). The AVBT technique is based on the Hueter-Volkmann law, ${ }^{1}$ which describes the physiological response to growing bones under mechanical compression. Compressive instrumentation on the convex side of a scoliotic curvature inhibits growth on the convex side while permitting the concave side to lengthen with growth, which progressively straightens the spine. ${ }^{2-4}$

Growth modulation via a flexible tether has been shown in animal models. In 2008, Newton and colleagues $^{5}$ demonstrated that, in an immature porcine model, a flexible polyethylene tether attached via pedicle screws along the anterolateral aspect of the spine could alter spinal morphology and induce a scoliotic deformity. This alteration was achieved while concurrently maintaining disc health and maximizing axial growth in a series of 12 mini pigs whose growth rates were similar to that of an adolescent growth spurt. Similar results have been demonstrated by Braun et $\mathrm{al}^{6}$ in a goat model.

In 2010, Crawford et $\mathrm{al}^{7}$ published the first report of a case of juvenile idiopathic scoliosis treated by anterior tethering. This new technique is less than a decade old with very few published clinical studies, possibly due to the short period since the technique's utilization and the lack of Food and Drug Administration (FDA) clearance in the United 
States until recent times. ${ }^{8}$ In August 2019, the FDA approved AVBT for use in skeletally immature populations under the Humanitarian Device Exemption mechanism. The arrival of this approval at a critical time will pave way for more clinical studies adding to ongoing research to understand the efficacy and improvise this new technique.

Existing clinical studies evaluating novel AVBT in skeletally immature children have questioned the midterm efficacy with concerns of overcorrection, cord rupture, return to theatre, or conversion to standard fusion surgery. ${ }^{9-11}$ The higher complication rate and revision rate in these series is attributable to the younger bone age of the cohort and the remaining skeletal growth contributing to overcorrection, curve progression, and tether failure.

AVBT has emerged as a fusionless alternative option to standard posterior spinal fusion, but a better understanding of surgical indications is needed to identify those patients likely to be successful. Among gray zones that need answering are ideal bone age, ideal curve, and optimal timing to AVBT.

Idiopathic scoliosis is a disorder of the growing spine. Growth and adolescent idiopathic scoliosis are interrelated. The younger the bone age, the higher the risk for progression of a scoliotic curve. The risk of scoliosis progression varies with growth and is proportional to the remaining growth. Scoliosis progression is high during the acceleration phase of puberty and it decreases progressively from Risser I through Risser V. It has been documented that in patients with idiopathic scoliosis, the main curve progression happens at the time of the most rapid adolescent skeletal growth, which is between 11 and 13 years of bone age in girls and between 13 and 15 years of bone age in boys. $^{12-18}$

Our hypothesis is that the novel AVBT technique in skeletally mature bone age AIS children (ie, those in deceleration phase of the growth) can restrict complications of overcorrection, cord breakage, return to theatre, or revision to fusion surgery associated with remaining growth potential that are documented in skeletally immature children who are in the acceleration phase of their growth. The current study investigates the safety and efficacy of this novel AVBT technique in the treatment of skeletally mature children with AIS.

\section{METHODS}

We prospectively studied patients with AIS who were operated on between 2018 and 2019 with the AVBT technique with a minimum of 1 year of follow-up. Our inclusion criteria for this novel technique were skeletally mature children (Risser $\geq 4$ and Sanders $\geq 7)^{19}$ with a single structural AIS curve $\left(40^{\circ}-80^{\circ}\right)$ with $\geq 50 \%$ flexibility on dynamic radiographs. We do supine awake manual traction and standing side bending dynamic radiographs routinely in all our patients to assess the flexibility of the curve. The curve should correct to $\geq 50 \%$ on dynamic radiographs to be eligible for the option of AVBT.

Institutional Review Board approval was obtained, and all patients and their families were counseled adequately to make an informed choice about nonfusion scoliosis correction using novel AVBT.

Ten patients met the criteria. Preoperative demographic data included gender, age at surgery, menarcheal status, height, and weight of the child. Collated pertinent clinical and radiographic data include skeletal maturity determined by Risser ${ }^{20}$ and Sanders, ${ }^{21}$ preoperative curve pattern, curve magnitude (coronal Cobb), flexibility, sagittal parameters (thoracic kyphosis and lumbar lordosis), and patient-reported outcome measure Scoliosis Research Society-22 (SRS-22) questionnaire. Perioperative data included surgical time, estimated blood loss, number of levels tethered, radiation, and average hospital stay. Data were recorded preoperatively and postoperatively at the first visit, at 6 months, and at 12 months.

\section{Surgical Technique}

The patient was placed in the lateral decubitus position with the convex side of the curve up. Patients underwent single lung ventilation. Standard minithoracotomy either in relation to the apex of the curve for main thoracic curves or at T9-10 for thoracolumbar/lumbar curves was used to allow better 3-dimensional assessment of the anatomy and confirm safe bicortical screw placement. Patients who were instrumented to L4 required a miniopen retroperitoneal approach. Vertebral levels were checked and confirmed using $\mathrm{C}$-arm fluoroscopy in anteroposterior and lateral positions. The disc spaces remain untouched. First, a 3-prong staple was placed on the anterior aspect of the vertebral 
Table 1. Demographic data.

\begin{tabular}{lc}
\hline Parameter & Value \\
\hline Age, mean \pm SD, y & $14.9 \pm 2.7$ \\
Gender, female, $n(\%)$ & $10(100)$ \\
Follow-up, mean \pm SD, mo & $24.1 \pm 3.6$ \\
Sanders score, mean \pm SD & $7.2 \pm 0.6$ \\
Risser score, mean \pm SD & $4.2 \pm 0.6$ \\
Structural curve & \\
$\quad$ Main thoracic, $n(\%)$ & $3(30)$ \\
$\quad$ Thoracolumbar/lumbar, $n(\%)$ & $7(70)$ \\
\hline
\end{tabular}

body, just anterior to the rib head. Subsequently, the screw hole was tapped, and the optimal length screw was placed. The remaining screws were placed similarly. The tether was passed distal to proximal and placed into the screw heads. The tether was connected to a pistol grip tensioning device, which allows graded compressive force up to $400 \mathrm{~N}$. Maximum intraoperative correction of the curve was obtained using a combination of apical translation, derotation, segmental compression, and sequential tensioning of the tether. Sequential rather than global tensioning is preferred with more tensioning at the apical region to achieve maximum correction intraoperatively. The amount of tension required depends on the magnitude of the curve and the remaining limited growth potential, and this is guided intraoperatively with fluoroscopy. Nine out of 10 patients were postmenarcheal at the time of AVBT, and all patients were skeletally mature with bone age of Risser $\geq 4$ and Sanders $\geq 7$. Although all were Risser 4 or above with skeletal maturity, some had not reached target height of parental height, and we also used this to eyeball how much tension to be applied to avoid overcorrection with remaining growth. A chest tube was placed, the hemithorax was irrigated, the lung was reinflated under direct vision, and the incisions were closed in layers.

\section{Statistical Analysis}

Data analysis was done using IBM SPSS version 13. Continuous variables are presented as mean \pm SD. A repeated analysis of variance test was performed to measure the difference between Cobb angle, thoracic kyphosis, and lumbar lordosis at three different time frames (preoperative, immediate postoperative, and at last follow-up). Wilcoxon signed rank test was used to compare pre- and postoperative SRS-22 scores. $P$ values of $<0.05$ were considered statistically significant.
Table 2. Perioperative data.

\begin{tabular}{lc}
\hline Perioperative Data & Mean \pm SD \\
\hline Duration of surgery (min) & $162.0 \pm 13.2$ \\
Estimated blood loss (mL) & $112.3 \pm 4.0$ \\
Radiation exposure (cGy) & $0.6 \pm 0.1$ \\
Radiation time (s) & $8.0 \pm 0.6$ \\
Number of instrumented vertebra & $7 \pm 0.9$ \\
\hline
\end{tabular}

\section{RESULTS}

All 10 patients were female. The mean age of the cohort at the time of surgery was $14.9 \pm 2.7$ years (range 12-17 years). The mean follow-up period was $24.1 \pm 3.6$ months (range 13 to 32 months). The mean height and weight values of the cohort were $157 \mathrm{~cm}$ and $44.4 \mathrm{~kg}$, respectively. The mean body mass index was $18.04 \mathrm{~kg} / \mathrm{m}^{2}$. Mean Risser and Sanders scores were $4.2 \pm 0.6$ and $7.2 \pm 0.6$, respectively. Nine out of 10 patients were postmenarcheal at the time of surgery. Three patients had major thoracic curves, and 7 patients had thoracolumbar/lumbar major curves (Table 1).

Mean preoperative Cobb angle was $52.0^{\circ} \pm 11.6^{\circ}$ (range $42^{\circ}$ to $80^{\circ}$ ). All underwent tethering with a mean of $7 \pm 0.9$ (range 6-9) levels with the upper instrumented vertebra being $\mathrm{T} 5$ and the lower instrumented vertebra being L4. The mean blood loss was $112.3 \pm 12.4 \mathrm{~mL}$, and the mean operative time was $162.0 \pm 13.2$ minutes. The mean radiation dose was $0.6 \pm 0.1 \mathrm{mGy}$, and the mean radiation exposure time was around $8.0 \pm 0.6$ seconds. The mean hospital stay was $3.5 \pm 0.5$ days. The mean gain in height was $2.7 \pm 0.6 \mathrm{~cm}$ (Table 2). The first erect postoperative radiograph showed a $70 \%$ correction with a mean Cobb angle of $15.9^{\circ} \pm$ $6.8^{\circ}$. The mean Cobb angle at the final follow-up was $15.3^{\circ} \pm 8.7^{\circ}$ (range $3^{\circ}$ to $28^{\circ}$ ). There was a $71 \%$ correction, and this correction was significant $(P<$ .0001). The mean preoperative thoracic kyphosis was $21.7^{\circ}$, which decreased to $15.5^{\circ}$ on first erect and then gradually increased to $20.3^{\circ}$ at the most recent follow-up $(P<.0001)$. The mean preoperative lumbar lordosis was $45.4^{\circ}$, which reduced to $43.3^{\circ}$ on first erect and increased to $47.5^{\circ}$ at the most recent follow up $(P<.0001)$ (Table 3). Mean preoperative and postoperative SRS-22 scores were $78.0 \pm 3.2$ and $92.5 \pm 3.1$, respectively. The change in SRS-22 score was significant $(P<.01)$ (Table 4$)$. There was no approach-related morbidity. There was no metal work-related complications or conversion to fusion until the last follow up. 
Table 3. Baseline and postoperative radiological measures.

\begin{tabular}{|c|c|c|c|c|c|}
\hline & Preoperative, Mean & First Erect, Mean & Most Recent, Mean & $\%$ Correction & $P$ Value \\
\hline Major Cobbs & 52.0 & 15.9 & 15.3 & 71 & $<.0001$ \\
\hline Thoracic kyphosis & 21.7 & 15.5 & 20.3 & -7 & $<.0001$ \\
\hline Lumbar lordosis & 45.4 & 43.3 & 47.5 & 5 & $<.0001$ \\
\hline
\end{tabular}

\section{DISCUSSION}

AVBT has the potential to correct scoliosis through its ability to modify spinal growth in skeletally immature children. ${ }^{7,22-24}$ There has been growing interest in exploring this alternative to traditional fusion. Although early promising outcomes were reported, there has been a concern about overcorrection or curve progression with continued growth in skeletally immature children. ${ }^{9,10,25}$ This preliminary study evaluated the safety and efficacy of scoliosis correction with AVBT in skeletally mature children with flexible AIS Lenke curves type 1 and 5 . We believe that intraoperative curve correction obtained using AVBT in older children in the deceleration phase of skeletal growth should be stabilized with remaining limited growth potential, thereby avoiding overcorrection or curve progression. Our early results demonstrate coronal Cobb angle correction and curve stabilization with the novel nonfusion AVBT technique (Figures 1 and 2). There was no neurological deficit, infection, or approach-related morbidity. No patient demonstrated worsening of the deformity, cord breakage, implant failure, necessity for revision surgery, or conversion to fusion at 1-year follow-up.

While time-tested traditional spinal fusion with the predictable clinical outcome would have been the gold standard option for our study patients, ${ }^{26-28}$ some studies suggest an increased risk of decreased spinal growth over the length of the fusion construct, decreased range of motion, decreased spinal mobility, adjacent disc degeneration, and back pain in the long term with spinal fusion. ${ }^{29-31}$ Wilk et al ${ }^{32}$ compared spinal motion among females with normal spines, those with idiopathic scoliosis who had not had spinal fusion, and those who had undergone fusion for idiopathic scoliosis. They reported no difference in any motion between the control and unfused groups. There was an overall $25 \%$ less total spinal motion in the fusion of surgical groups than the unfused group. Overall diminished spinal motion is measured in patients who have had spinal fusions. Although stiffness in the operated curves is expected, compensatory hypermobility in the unfused segments does not occur, resulting in a net loss of flexibility compared with controls.

Although numerous animal studies have documented the biomechanical basis for growth modulation with flexible tether, ${ }^{5,6,33-38}$ published clinical series reporting its efficacy are limited. In 2014, Samdani et $\mathrm{al}^{22}$ reported the first series of 11 patients of AVBT for idiopathic thoracic scoliosis with a mean age of 12.3 years. Preoperative thoracic Cobb angle and compensatory lumbar curves corrected on average from $44.2^{\circ}$ to $13.5^{\circ}$ and $25.1^{\circ}$ to $7.2^{\circ}$, respectively, at 2 -year follow-up with approximately $70 \%$ correction on average for both curves. They reported a return to the operating room in 2 patients to loosen the tether and prevent overcorrection. In 2015, Samdani et $\mathrm{al}^{23}$ expanded their sample size and reported results on their first 32 patients that underwent AVBT. The mean age was 12 years, the mean Sanders score was 3.2, and all patients had a minimum 1-year follow-up. Thoracic curve correction improved from a mean preoperative magnitude of $42.8^{\circ}$ to $17.9^{\circ}$ at the most recent follow-up. They documented one case of prolonged atelectasis and overcorrection in 3 patients.

In 2017, Boudissa et $\mathrm{al}^{24}$ published 1-year outcomes of AVBT for thoracic scoliosis in a series of 6 patients with a mean age of 11.2 years. They

Table 4. Preoperative and postoperative SRS-22 scores. Results are expressed as mean \pm SD for the total sum of each domain divided by the number of items answered; domain subtotal scores are in parentheses.

\begin{tabular}{|c|c|c|c|c|c|c|c|}
\hline & Pain & Function/Activity & Body Image & Mental Health & Mean Total Score & Satisfaction & $P$ Value \\
\hline Preoperative & $74 \pm 2.2(3.7 \pm 0.1)$ & $82 \pm 3.0(4.1 \pm 0.2)$ & $76 \pm 2.3(3.8 \pm 0.1)$ & $80 \pm 2.4(4 \pm 0.1)$ & $78 \pm 3.2(3.9 \pm 0.2)$ & & $<.01^{\mathrm{a}}$ \\
\hline Postoperative & $84 \pm 2.4(4.2 \pm 0.1)$ & $86 \pm 2.3(4.3 \pm 0.1)$ & $92 \pm 1.6(4.6 \pm 0.1)$ & $90 \pm 1.8(4.5 \pm 0.1)$ & $88 \pm 3.1(4.4 \pm 0.2)$ & 4.5 & \\
\hline$\%$ Improvement & 13 & 5 & 21 & 13 & 13 & & \\
\hline
\end{tabular}

Abbreviation: SRS, Scoliosis Research Society.

${ }^{a}$ Mean total preoperative versus postoperative score. 

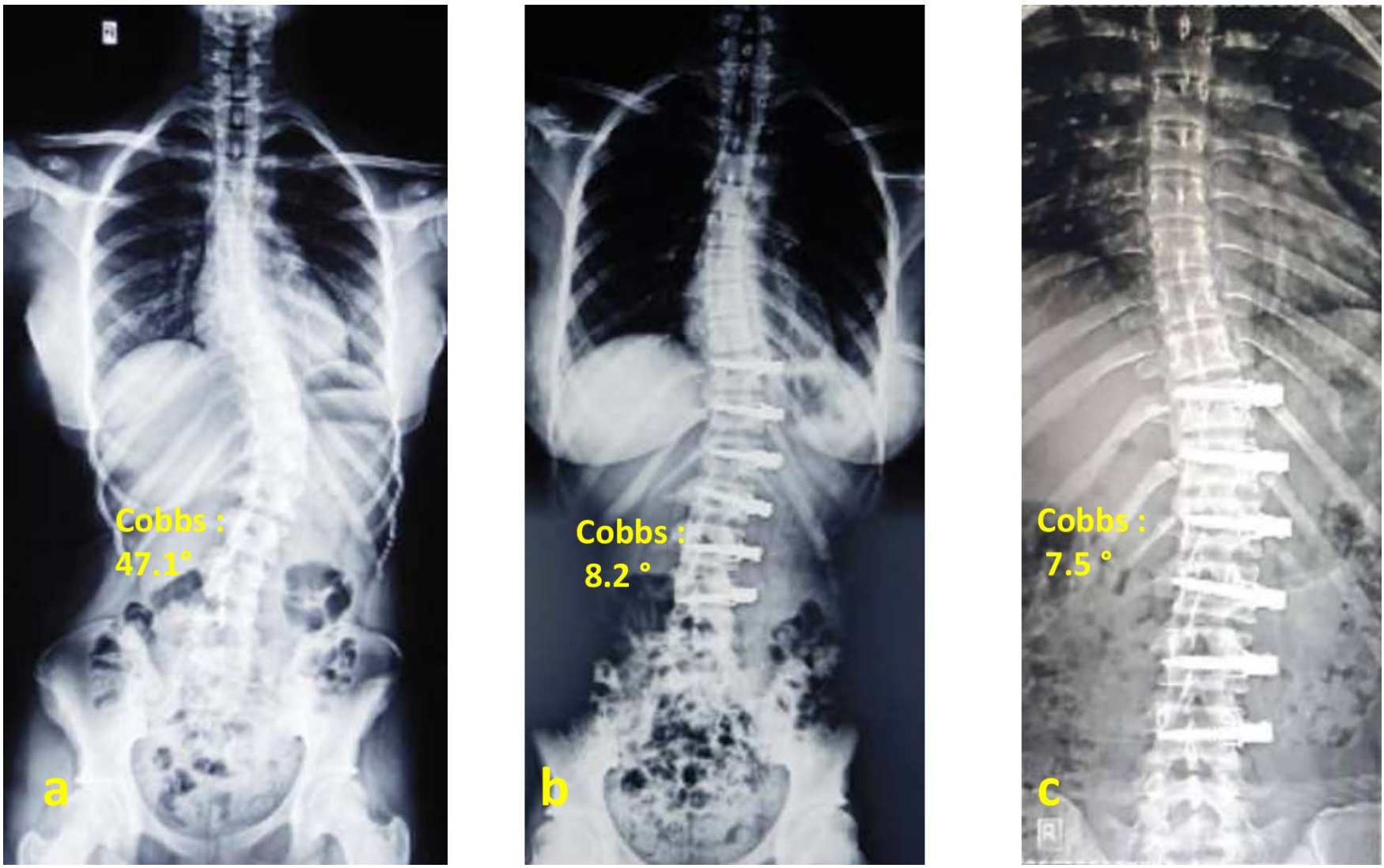

Figure 1. Fifteen-year-old girl with Risser 5 and Sanders 7 presented with Lenke $5 \mathrm{CN}$ (Thoracolumbar curve [type 5] with central sacral vertical line [CSVL] medial to apical pedicle $[\mathrm{C}]$ with normal kyphosis [N]) adolescent idiopathic scoliosis. (a) Preoperative radiograph shows a Cobb angle of $47.1^{\circ}$. (b) $I \mathrm{mmediate}$ postoperative erect radiograph with Cobb angle measuring $8.2^{\circ}$ (83\% correction). (c) At the 1.5-year follow-up, the deformity corrected to a Cobb angle measuring $7.5^{\circ}$ (further $8 \%$ correction).
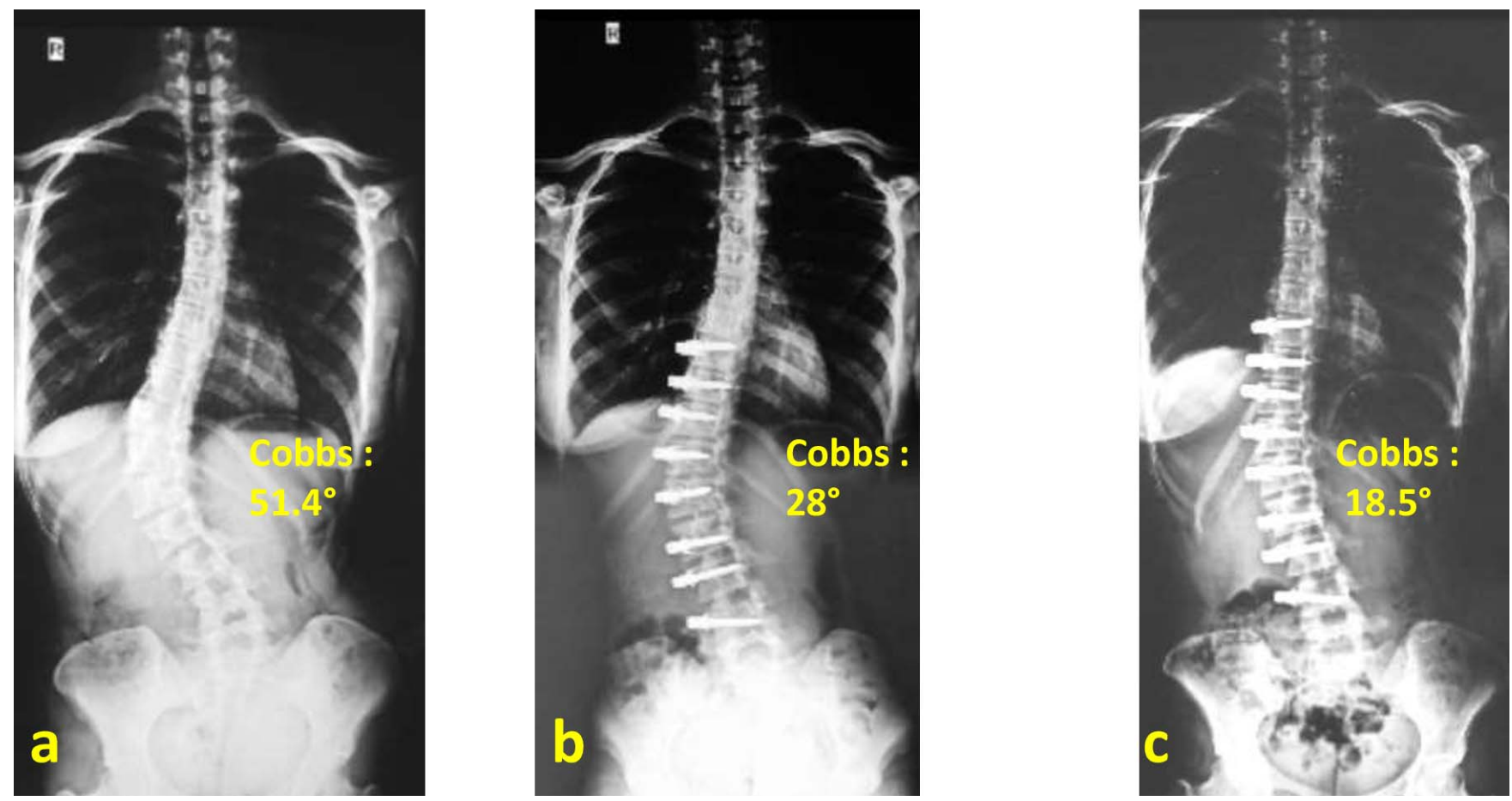

Figure 2. Fourteen-year-old girl with Risser 5 and Sanders 7 presented with Lenke $5 \mathrm{CN}$ (Thoracolumbar curve [type 5] with central sacral vertical line [CSVL] medial to apical pedicle [C] with normal kyphosis [N]). (a) Preoperative radiograph shows a Cobb angle of $51.4^{\circ}$. (b) Immediate postoperative erect radiograph with Cobb angle measuring $28.0^{\circ}$ ( $46 \%$ correction). (c) At the 1-year follow-up, the deformity corrected to a Cobb angle measuring $18.5^{\circ}$ (further $33 \%$ correction). 
Table 5. Brief overview of published studies on anterior vertebral body tethering.

\begin{tabular}{|c|c|c|c|c|c|c|c|c|c|}
\hline $\begin{array}{l}\text { Serial } \\
\text { Number }\end{array}$ & Author & $N$ & $\begin{array}{l}\text { Average } \\
\text { Age, y }\end{array}$ & Risser & Follow-up & $\begin{array}{l}\text { Preoperative } \\
\text { Cobbs, }{ }^{\circ}\end{array}$ & $\begin{array}{c}\text { Final Follow-up } \\
\text { Cobbs, }\end{array}$ & $\begin{array}{l}\text { Average \% } \\
\text { Correction }\end{array}$ & Complications \\
\hline 1 & Samdani $2014^{22}$ & 11 & 12.3 & $\leq 2$ & $24 \mathrm{mo}$ & $\begin{array}{l}\mathrm{T}: 44.2 \pm 9.0 \\
\mathrm{~L}: 25.1 \pm 8.7\end{array}$ & $\begin{array}{l}\mathrm{T}: 13.5 \pm 11.6 \\
\mathrm{~L}: 7.2 \pm 5.1\end{array}$ & 70 & $\begin{array}{l}2 \text { surgical loosening of } \\
\text { the tension due to } \\
\text { overcorrection }\end{array}$ \\
\hline 2 & Samdani $2015^{23}$ & 32 & 12 & $\leq 2$ & $12 \mathrm{mo}$ & $\begin{array}{l}\mathrm{T}: 42.8 \pm 8.0 \\
\mathrm{~L}: 25.2 \pm 7.3\end{array}$ & $\begin{array}{l}\mathrm{T}: 17.9 \pm 11.4 \\
\mathrm{~L}: 12.6 \pm 9.4\end{array}$ & 58 & $\begin{array}{l}1 \text { patient with transient } \\
\text { atelectasis }\end{array}$ \\
\hline 3 & Boudissa $2017^{24}$ & 6 & 11.2 & 0 & $12 \mathrm{mo}$ & $\begin{array}{l}\mathrm{T}: 45 \pm 10 \\
\quad \mathrm{~L}: 33 \pm 5\end{array}$ & $\begin{array}{l}\text { T: } 38 \pm 7 \\
\quad \text { L: } 25 \pm 9\end{array}$ & T: 15 L: 24 & No complications \\
\hline 4 & Newton $2018^{9}$ & 17 & 11 & 0 & 24 to $28 \mathrm{mo}$ & $\mathrm{T}: 52 \pm 10$ & $\mathrm{~T}: 27 \pm 20$ & 51 & $\begin{array}{l}4 \text { patients underwent } \\
\text { fusion, and } 2 \text { patients } \\
\text { with transient atelectasis }\end{array}$ \\
\hline 5 & Wong et al $2019^{25}$ & 5 & 12.2 & 0 & $4 \mathrm{y}$ & $\mathrm{T}: 37.2-44.0$ & $\mathrm{~T}: 12.2-33.3$ & 55 & $\begin{array}{l}2 \text { patients had over correction, } \\
1 \text { patient had truncal listing, } \\
1 \text { patient had pneumothorax, } \\
1 \text { patient had pleural effusion, } \\
1 \text { patient had curve progression/ } \\
\text { distal decompensation, and } 2 \\
\text { patients underwent spinal fusion }\end{array}$ \\
\hline 6 & $\begin{array}{l}\text { Hoernschemeyer } \\
\text { et al } 2020^{10}\end{array}$ & 29 & 12.7 & $\begin{array}{l}\leq 1=14 \\
2-4=15\end{array}$ & $3.2 \mathrm{y}$ & $\begin{array}{l}\mathrm{T}: 48^{\circ} \pm 4^{\circ} \\
\mathrm{L}: 38^{\circ} \pm 5^{\circ}\end{array}$ & $\begin{array}{l}\mathrm{T}: 23^{\circ} \pm 7^{\circ} \\
\mathrm{L}: 24^{\circ} \pm 7^{\circ}\end{array}$ & $\begin{array}{l}\text { T: } 52 \\
\text { L: } 36\end{array}$ & $\begin{array}{l}14 \text { patients had suspected } \\
\text { tether rupture } \geq 1 \text { level, } \\
2 \text { patients underwent } \\
\text { posterior spinal fusion, } \\
4 \text { patients had tether } \\
\text { revision }\end{array}$ \\
\hline 7 & Current study & 10 & 14.9 & 4.2 & $24.1 \mathrm{mo}$ & $52 \pm 11.6$ & $15.3 \pm 8.7$ & 71 & No complications \\
\hline
\end{tabular}

reported correction of mean preoperative thoracic Cobb angle of $45^{\circ}$ and lumbar Cobb angle of $33^{\circ}$ to $38^{\circ}$ and $25^{\circ}$, respectively, at 1 -year follow-up with no patients requiring fusion.

In 2018, Newton et $\mathrm{al}^{9}$ reported a retrospective case series of 17 patients with a mean age of 11 years and 2-4 years follow-up. All patients underwent thoracoscopic tethering of the thoracic curve, and a documented correction of Cobb angle from $52^{\circ}$ to $27^{\circ}$ was observed at the most recent follow-up. In their series, a higher revision rate was documented with 7 patients returning to the operating room during the study period (4 tether removals for overcorrection, 1 addition of a lumbar tether, 1 tether replacement due to breakage, and 1 patient revised to a posterior spinal fusion secondary to curve progression). Additionally, 3 patients were indicated for posterior spinal fusion at the time of publication. With longer follow-up than previous studies, the authors concluded that, although AVBT tethering is powerful, there also appears to be variable results, and a better understanding of surgical indications is needed to identify those patients likely to be successful.

In 2019, Wong et $\mathrm{al}^{25}$ reported mixed outcome at midterm (4 years follow-up) in a small series of 5 patients aged 9-12 years who had thoracoscopicassisted AVBT technique using a new device composed of a braided ultra-high molecular weight polyethylene cord. They observed distal decompen- sation, curve progression, and overcorrection in 3 patients, 2 of whom required fusion. In their series, actual correction by growth modulation was noted in patients with open triradiate cartilage, whereas curve stabilization was noted in patients with closed triradiate cartilage. The authors concluded that understanding patient and curve characteristics and the optimal timing of tether application and surgical method are all critical for consistent results of the AVBT technique.

Newton et $\mathrm{al}^{9}$ in their series observed a high revision rate due to tether rupture, overcorrection, or curve progression. They observed progressive correction of the curve during the first 24 months after AVBT, documenting peak correction during the 6 month to 1 year after AVBT. However, after 18 months, the results were less consistent, with some curves beginning to progress, some continuing to correct, and some overcorrecting. They highlighted that a 1- to 2-year time period seemed to mark a critical point, with four tethers breaking, 3 patients undergoing tether removal or revision, and 1 patient having continued lumbar curve progression to the point of requiring posterior spinal fusion. Newton et al's cohort was younger (11 years) and less skeletally mature (Risser 0 ) than the previously published cohort (Table 5), which may attribute to higher revision rate due to remaining skeletal growth contributing to overcorrection, curve progression, and tether failure. 
In 2019, Trobisch et $\mathrm{al}^{7}$ published a nonsystematic review on AVBT and coined the term "Dynamic Scoliosis Correction" (DCS) as an alternative nomenclature for "Anterior Vertebral Body Growth Modulation" or "Anterior Scoliosis Correction" for the use in German literature to avoid translation confusion. In this narrative review, the authors proposed their treatment algorithm for DCS from their unit initial experience with 60 patients treated using DCS with tether. They proposed a new scoliosis classification following DSC's indication and highlighted that the higher the scoliosis classification the lower the strength of indication for DSC. However, their results and subset analysis are yet to be validated and presented. Although, based on clinical experience, the newer classification must be validated both internally and externally through prospective longitudinal studies.

In 2020, Hoernschemeyer et $\mathrm{al}^{10}$ reported a retrospective case series of 29 children with a mean age of $12.7 \pm 1.5$ years at the time of AVBT and with a mean follow-up of 3.2 years. In their series, they reported suspected broken tether at $\geq 1$ level in 14 patients $(48 \%), 2$ patients underwent posterior spinal fusion, and 4 patients had tether revision. The overall revision rate was $21 \%$ (6 of 29). Although the children in this series are slightly older and skeletally more mature than previously published series, a significant proportion of children were in the acceleration phase of growth $(48 \%$ Risser $<1$, $55 \%$ Sanders $<4$ ), and this could attribute to the observed complications in their series.

In 2020, Newton et $\mathrm{al}^{11}$ reported a retrospective comparative series of thoracic idiopathic scoliosis treated with AVBT and a matched cohort treated with posterior spinal fusion (PSF). In their study, they included children with primary thoracic idiopathic scoliosis with a curve magnitude of $40^{\circ}$ to $67^{\circ}$, Risser stage $\leq 1$, and mean age of $12 \pm 2$ at the time of surgery with a minimum of 2 years of follow-up. They reported that both AVBT and PSF resulted in a postoperative correction. However, at final followup, they observed more residual deformity in the AVBT group than the PSF group and also documented 9 revisions in the AVBT group (3 converted to PSF and 3 more pending). Twelve patients $(52 \%)$ had evidence of broken tether out of which 4 required revision surgery. Revisions occurred at a mean postoperative time of 2.3 years (range 1.2 to 3.7 years). Again, the higher revision rate and residual deformity noted in the AVBT cohort is attributable to the $2-3$ years of remaining growth potential of the children, as all were in the acceleration phased of skeletally immature bone age (91\% Risser 0, 9\% Risser 1) at the time of index procedure. At the time of the final follow-up (mean 3.4 years), half of the patients $(52 \%)$ in the AVBT cohort met their prior definition of clinical success with a residual curve of $<35$ compared with all of the patients in the PSF cohort. Although deformity correction can be predicted with greater confidence following standard PSF, if the goal is primarily to avoid a spinal fusion and the associated loss of truncal motion while reducing the risk of scoliosis progression at maturity by reducing the curve below 50 , this was accomplished in $74 \%$ of patients in their AVBT group. Despite observed higher residual deformity and complication rate with AVBT, they did not document any difference in the patientreported outcome measures between the groups.

In the current series, the patients are older and more skeletally mature than all previously published cohorts (Table 5), and the maximum coronal correction was obtained intraoperatively. We observed subsequent minimal correction and curve stabilization at 1 year after AVBT. Our cohort is skeletally mature (Risser $\geq 4$ and Sanders $\geq 7)^{19}$ with limited growth potential. AVBT with our concept of maximal intraoperative correction helped to achieve good postoperative correction. The rational for our technique of maximum intraoperative correction is to reduce residual deformity, as growth-guided modulation is less predictable in children with skeletally mature bone age. With the less remaining growth potential of our cohort, the AVBT has stabilized the curve correction without the risk of overcorrection, tether rupture, or progression of the deformity.

Our patients are under close surveillance, and given less remaining skeletal growth potential, we anticipate a lesser number of complications documented by both Newton et $\mathrm{al}^{9,11}$ and Hoernschemeyer et $\mathrm{al}^{10}$ (ie, curve overcorrection, curve progression, tether rupture, or any revision).

Our study has few unique features compared with previously published cohorts. First, our cohort is older (mean age 14.9 years) and skeletally mature (mean Risser $4.2 \pm 0.6$ and Sanders $7.2 \pm 0.6$ ) (Table 5). Second, our series has a mix of Lenke 1and 5-type curves with caudal instrumentation to the L4 level, while previous studies were exclusively Lenke 1-type curves with thoracic instrumentation, 
except the most recent Hoernschemeyer et al series. Third, our study evaluated the patient-reported outcome measure SRS-22 and documents statistically significant improvement in the mean SRS score from preoperative to 1 year after surgery, reflecting their satisfaction with the early outcome.

\section{Limitations}

Small sample size, heterogeneous curve patterns, and lack of a control group are the limitations of this preliminary study evaluating a novel surgical technique. Also, we have not objectively measured spinal range of motion to support the claim of preservation of motion by this novel technique. Prior sample size calculation and power analysis were not feasible as this novel surgical technique effect size is not well documented.

\section{Conclusion}

Our preliminary experience with this novel AVBT as an alternative technique to fusion to stabilize progressive idiopathic scoliosis in skeletally mature children is promising, but it has to stand the test of time. Long-term outcome of large series documenting the ideal candidate for surgery, ideal curve characteristics, ideal timing of surgery, and magnitude of intraoperative curve correction will be critical for this novel technique to reduce the reoperation rate or convert into fusion surgery.

\section{ACKNOWLEDGMENTS}

Authors also wish to thank Dr Raveesh Mayya, Assistant Professor at the New York University, for his suggestion on statistical analysis.

\section{REFERENCES}

1. Mehlman CT, Araghi A, Roy DR. Hyphenated history: the Hueter-Volkmann law. Am J Orthop (Belle Mead NJ). 1997;26(11):798-800.

2. Stokes IA, Spence H, Aronsson DD, Kilmer N. Mechanical modulation of vertebral body growth. Implications for scoliosis progression. Spine (Phila Pa 1976). 1996;21(10):1162-1167. doi:10.1097/00007632-19960515000007

3. Akel I, Yazici M. Growth modulation in the management of growing spine deformities. J Child Orthop. 2009;3(1):1-9. doi:10.1007/s11832-008-0145-6

4. Bonsignore-Opp L, Murphy J, Skaggs D, et al. Growth modulation for childhood scoliosis: from where have we come, and where are we going? J Pediatr Soc North Am 2019;1(1).

5. Newton PO, Farnsworth CL, Faro FD, et al. Spinal growth modulation with an anterolateral flexible tether in an immature bovine model: disc health and motion preservation. Spine (Phila Pa 1976). 2008;33(7):724-733. doi:10.1097/BRS. 0b013e31816950a0.

6. Braun JT, Ogilvie JW, Akyuz E, Brodke DS, Bachus KN. Creation of an experimental idiopathic-type scoliosis in an immature goat model using a flexible posterior asymmetric tether. Spine (Phila Pa 1976). 2006;31(13):1410-1414. doi:10. 1097/01.brs.0000219869.01599.6b

7. Crawford CH III, Lenke LG. Growth modulation by means of anterior tethering resulting in progressive correction of juvenile idiopathic scoliosis: a case report. J Bone Joint Surg Am. 2010;92(1):202-209. doi:10.2106/JBJS.H.01728.

8. Trobisch PD, Kobbe P, Baroncini A. Dynamic scoliosis correction as alternative treatment for patients with adolescent idiopathic scoliosis: a non-fusion surgical technique. Z Orthop Unfall. 2020;158(6):641-646. doi:10.1055/a-0983-1265

9. Newton PO, Kluck DG, Saito W, Yaszay B, Bartley CE, Bastrom TP. Anterior spinal growth tethering for skeletally immature patients with scoliosis: a retrospective look two to four years postoperatively. J Bone Joint Surg Am. 2018;100(19):1691-1697. doi:10.2106/JBJS.18.00287

10. Hoernschemeyer DG, Boeyer ME, Robertson ME, et al. Anterior vertebral body tethering for adolescent scoliosis with growth remaining: a retrospective review of 2 to 5-year postoperative results. J Bone Joint Surg Am. 2020;102(13):1169-1176. doi:10.2106/JBJS.19.00980

11. Newton PO, Bartley CE, Bastrom TP, Kluck DG, Saito W, Yaszay B. Anterior spinal growth modulation in skeletally immature patients with idiopathic scoliosis: a comparison with posterior spinal fusion at 2 to 5 years postoperatively. $J$ Bone Joint Surg Am. 2020;102(9):769-777.

12. Dimeglio A, Bonnel F, Canavese F. Normal growth of the spine and thorax. In: Akbarnia B, Yazici M, Thompson $\mathrm{GH}$, eds. The Growing Spine. New York, NY: Springer; 2009:11-41.

13. Dimeglio A, Canavese F. The growing spine: how spinal deformities influence normal spine and thoracic cage growth. Eur Spine J. 2012;21(1):64-70. doi:10.1007/s00586-011-1983-3

14. DiMeglio A, Canavese F, Charles YP. Growth and adolescent idiopathic scoliosis: when and how much? J Pediatr Orthop. 2011;31(1 Suppl):S28-S36. doi:10.1097/BPO. 0b013e318202c25d

15. Dimeglio A. Growth in pediatric orthopaedics. In: Morrissy T, Weinstein SL, eds. Lovell \& Winter's Pediatric Orthopaedics. 6th ed. Philadelphia, PA: Lippincott, William \& Wilkins; 2005:35-61

16. Dimeglio A, Canavese F. Progression or not progression? How to deal with adolescent idiopathic scoliosis during puberty. J Child Orthop. 2013;7(1):43-49. doi:10.1007/s11832012-0463-6

17. Lonstein JE, Carlson JM. The prediction of curve progression in untreated idiopathic scoliosis during growth. $J$ Bone Joint Surg Am. 1984;66(7):1061-1071.

18. Charles YP, Daures JP, de Rosa V, Diméglio A. Progression risk of idiopathic juvenile scoliosis during pubertal growth. Spine (Phila Pa 1976). 2006;31(17):1933-1942. doi:10. 1097/01.brs.0000229230.68870.97

19. Bassett WP, Antonacci MD, Cuddihy LA, Cerrone JL, Haas AR, Betz RR. Non-fusion anterior scoliosis correction (ASC): comparison of outcomes in skeletally immature vs. skeletally mature patients with adolescent idiopathic scoliosis. 
Podium presentation at: 26th IMAST Meeting, Amsterdam and Eurospine; September 18, 2019; Helsinki, Finland.

20. Risser JC. The iliac apophysis; an invaluable sign in the management of scoliosis. Clin Orthop. 1958;11:111-119.

21. Sanders JO, Browne RH, McConnell SJ, Margraf SA, Cooney TE, Finegold DN. Maturity assessment and curve progression in girls with idiopathic scoliosis. J Bone Joint Surg Am. 2007;89(1):64-73. doi:10.2106/JBJS.F.00067

22. Samdani AF, Ames RJ, Kimball JS, et al. Anterior vertebral body tethering for idiopathic scoliosis: two-year results. Spine (Phila Pa 1976). 2014;39(20):1688-1693. doi:10. 1097/BRS.0000000000000472

23. Samdani AF, Ames RJ, Kimball JS, et al. Anterior vertebral body tethering for immature adolescent idiopathic scoliosis: one-year results on the first 32 patients. Eur Spine J. 2015;24(7):1533-1539. doi:10.1007/s00586-014-3706-Z

24. Boudissa M, Eid A, Bourgeois E, Griffet J, Courvoisier A. Early outcomes of spinal growth tethering for idiopathic scoliosis with a novel device: a prospective study with 2 years of follow-up. Childs Nerv Syst. 2017;33(5):813-818. doi:10.1007/ s00381-017-3367-4

25. Wong H, Ruiz J, Newton P, Gabriel Liu K. Non-fusion surgical correction of thoracic idiopathic scoliosis using a novel, braided vertebral body tethering device. JBJS Open Access. 2019;4(4):e0026. doi:10.2106/jbjs.oa.19.00026

26. Hwang SW, Samdani AF, Marks M, et al. Five-year clinical and radiographic outcomes using pedicle screw only constructs in the treatment of adolescent idiopathic scoliosis. Eur Spine J. 2013;22(6):1292-1299. doi:10.1007/s00586-0122625-0

27. Suk SI, Lee SM, Chung ER, Kim JH, Kim SS. Selective thoracic fusion with segmental pedicle screw fixation in the treatment of thoracic idiopathic scoliosis: more than 5-year follow-up. Spine (Phila Pa 1976). 2005;30(14):1602-1609. doi:10.1097/01.brs.0000169452.50705.61

28. Lehman RA Jr, Lenke LG, Keeler KA, et al. Operative treatment of adolescent idiopathic scoliosis with posterior pedicle screw-only constructs: minimum three-year follow-up of one hundred fourteen cases. Spine (Phila Pa 1976). 2008;33(14):1598-1604. doi:10.1097/BRS.0b013e318178872a

29. Danielsson AJ, Romberg K, Nachemson AL. Spinal range of motion, muscle endurance, and back pain and function at least 20 years after fusion or brace treatment for adolescent idiopathic scoliosis: a case-control study. Spine (Phila $\mathrm{Pa}$ 1976). 2006;31(3):275-283. doi:10.1097/01.brs.0000197652. 52890.71

30. Kepler CK, Meredith DS, Green DW, Widmann RF. Long-term outcomes after posterior spine fusion for adolescent idiopathic scoliosis. Curr Opin Pediatr. 2012;24(1):68-75. doi:10.1097/MOP.0b013e32834ec982

31. Green DW, Lawhorne TW III, Widmann RF, et al. Long-term magnetic resonance imaging follow-up demonstrates minimal transitional level lumbar disc degeneration after posterior spine fusion for adolescent idiopathic scoliosis. Spine (Phila Pa 1976). 2011;36(23):1948-1954. doi:10.1097/BRS. 0b013e3181ff1ea9
32. Wilk B, Karol LA, Johnston CE II, Colby S, Haideri N. The effect of scoliosis fusion on spinal motion: a comparison of fused and nonfused patients with idiopathic scoliosis. Spine (Phila Pa 1976). 2006;31(3):309-314. doi:10.1097/01.brs. 0000197168.11815.ec

33. Newton PO, Fricka KB, Lee SS, Farnsworth CL, Cox TG, Mahar AT. Asymmetrical flexible tethering of spine growth in an immature bovine model. Spine (Phila Pa 1976). 2002;27(7):689-693. doi:10.1097/00007632-200204010-00004

34. Newton PO, Upasani VV, Farnsworth CL, et al. Spinal growth modulation with use of a tether in an immature porcine model. J Bone Joint Surg Am. 2008;90(12):2695-2706. doi:10. 2106/JBJS.G.01424

35. Moal B, Schwab F, Demakakos J, et al. The impact of a corrective tether on a scoliosis porcine model: a detailed 3D analysis with a 20 weeks follow-up. Eur Spine $J$. 2013;22(8):1800-1809. doi:10.1007/s00586-013-2743-3

36. Upasani VV, Farnsworth CL, Chambers RC, et al. Intervertebral disc health preservation after six months of spinal growth modulation. J Bone Joint Surg Am. 2011;93(15):14081416. doi:10.2106/JBJS.J.00247

37. Chay E, Patel A, Ungar B, et al. Impact of unilateral corrective tethering on the histology of the growth plate in an established porcine model for thoracic scoliosis. Spine (Phila Pa 1976). 2012;37(15):E883-E889. doi:10.1097/BRS. $0 \mathrm{~b} 013 \mathrm{e} 31824 \mathrm{~d} 973 \mathrm{c}$

38. Newton PO, Glaser DA, Doan JD, Farnsworth CL. 3D visualization of vertebral growth plates and disc: the effects of growth modulation. Spine Deform. 2013;1(5):313-320. doi:10. 1016/j.jspd. 2013.07.005

Disclosures and COI: No funds were received in support of this work. No relevant financial activities are outside the submitted work. There are no potential conflicts of interest affecting the manuscript. Author Dr Sajan K. Hegde is a consultant to Globus Medicals and has intellectual property rights with royalties.

Corresponding Author: Keyur Kantilal Akbari, Opd No 104, Counter number 9, Apollo Hospitals ,Greams Lane, Chennai 600006, India. Phone: +918980808179/+919879137187; Email: keyur21088@yahoo.co.in.

Published 0 Month 2021

This manuscript is generously published free of charge by ISASS, the International Society for the Advancement of Spine Surgery. Copyright (C) 2021 ISASS. To see more or order reprints or permissions, see http://ijssurgery.com. 